\title{
A Graceful Exit: Redefining Terminal to Expand the Availability of Physician-Facilitated Suicide
}

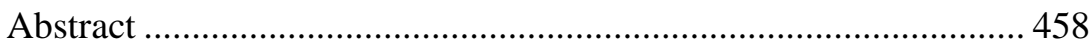

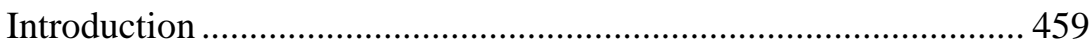

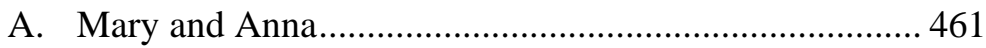

B. Exiting Gracefully ....................................................... 462

I. Legalizing the Use of Physician-Facilitated Suicide............. 464

A. Enabling Physician-Facilitated Suicide Through Judicial Interpretation.................................................. 465

B. Legalizing Physician-Facilitated Suicide Through

Legislative Action ....................................................... 468

1. Necessary Characteristics of the Patient.................... 468

2. The Mandated Procedures ....................................... 470

II. Regulating the Use of Physician-Facilitated Suicide ............ 472

A. Legislative Solutions to Common Concerns Over

Physician-Facilitated Suicide ......................................... 472

1. Targeting the Elderly and Disabled........................... 472

2. Encouragement for Suicidal Persons........................ 473

3. Weeding Out Poor Patients and Patients of Color.... 475

4. Overeager Physicians ............................................... 477

5. The Floodgates ...................................................... 478

* Leon \& Gloria Plevin Professor of Law, Cleveland-Marshall College of Law; B.A., Grambling State University; M.P.A., Humphrey Institute; J.D., University of Minnesota School of Law; L.L.M., University of Houston Law Center. I would like to thank Dean Craig Boise and the Cleveland-Marshall Fund for providing financial support for this Article. I would also like to thank the members of my scholarship support group: Professors Heidi Robertson, Alan Weinstein, Matthew Green, and Kristina Niedringhaus. I would like to thank my assistant Diane Adams for assisting in the editing process. Finally, I would like to thank the Fondation Brocher for giving me the opportunity to spend two months in Geneva, Switzerland, so that I could finish my research. 
B. Issues Yet to be Resolved by the Legislature 479

1. Death Tourism.

2. Unused Medication....................................................... 480

3. Doctor Shopping................................................. 482

III. Expanding the Availability of Physician-Facilitated Suicide. 484

A. Planning for Terminal .................................................. 484

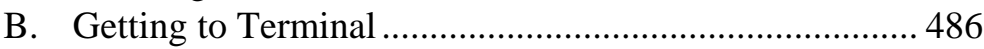

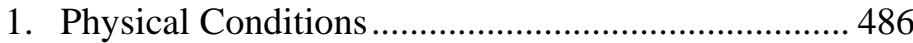

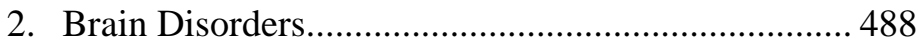

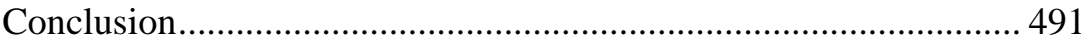

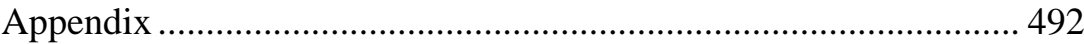

\begin{abstract}
For almost ten years, Oregon stood alone as the state that permitted terminally ill persons to choose the time and manner of their deaths. Finally, in 2009, Oregon received company when the State of Washington's physician-facilitated suicide statute officially went into effect in March of that year. Supporters of the statutes hailed the enactments as a victory for persons seeking to die with dignity. Persons from groups like Compassion \& Choices vowed to seek similar legislation in the remaining states. Representatives from the Washington State Medical Association, hospice groups and hospitals argued that the mandates of the statutes place physicians in an unnatural position. In particular, the Medical Association's spokesman stated that physicians take an oath to save lives, not end them.
\end{abstract}

Despite these objections, the number of persons in the country who support physician-facilitated suicide has continued to grow. At the end of 2009, the Montana Supreme Court indicated that physicianfacilitated suicide is not against the state's public policy.

This Article does not join the debate about the legalization of physician-assisted suicide. Rather, I have two goals. First, I suggest ways the current statutes could be improved to address the concerns of the critics of physician-facilitated suicide. Second, I recommend ways to expand the availability of physician-facilitated suicide so that more people can exit gracefully. To that end, I analyze the laws in Oregon and Washington and argue that the current statutes need to be amended to effectuate their legislative purposes. That analysis shows that the legislatures in those states attempted to regulate the 
process in order to protect the interests of terminally ill patients and physicians. The statutory mandates are a step in the right direction, but much work remains to truly honor those interests.

The statutes should be amended to close certain loopholes and to ensure that the physician-facilitated suicide option is available to all of the patients who need it. Persons suffering from physical conditions that will lead to death within six months should not be the only persons permitted to exit gracefully. As long as the safeguards included in the statutes are followed, there is no good reason to prohibit persons suffering from irreversible and incurable physical diseases that lead to death from being classified as terminal.

In addition, persons diagnosed with irreversible and incurable brain disorders, like severe dementia or Alzheimer's disease, should be able to avail themselves of the rights provided by the physicianfacilitated suicide statutes. Alzheimer's patients suffer a slow, painful death. They revert to childhood and forget everyone around them. The mental death they suffer is similar to the physical death experienced by terminally physically ill patients. During the early stages of the disease, most Alzheimer sufferers are still competent enough to request physician-facilitated suicide. Therefore, the statutes should be amended or interpreted to give them that option.

"Life is pleasant. Death is peaceful. It's the transition that's troublesome." 1

\section{INTRODUCTION}

$\mathrm{M}$ y English is good, my Spanish is okay, and my French is nonexistent. I was panicking. I was in a foreign country and I could not speak the language. My hike through the woods had turned into a disaster after some unknown critter bit me. I went to the Swiss doctor prepared to use sign language to get her to understand that I needed to know that it was not a tick bite. The doctor smiled and said "hello." Thankfully, she spoke English. After she examined the bite, she assured me that it was just an ordinary insect bite.

While she wrote out a prescription for antibacterial cream, she asked me the reason for my stay in Switzerland. I told her about my research on physician-assisted suicide. In response, she told me that she had written a prescription for lethal medicine earlier that week so

1 This as an Isaac Asimov quote. See, e.g., Authors: Isaac Asimov, QUOTE DB, http://www.quotedb.com/authors/isaac-asimov (last visited Oct. 17, 2012). 
a man could end his life. The doctor's eyes became misty as she described the eighty-two year old man who had suffered from terminal stomach cancer. Because her only involvement was writing the prescription, the doctor stated that she did not feel like she had assisted in the suicide. She viewed herself as more of a facilitator. I agreed with her assessment. $^{2}$

While conducting research for this article, I came across the quote, "Pain is inevitable; suffering is optional." 3 With the advances in medical technology and the creation of new drugs, health care providers have taken great steps to ensure that patients can manage their pain effectively. Thus, the average person does not have to suffer the pain brought on by injury, disease, and age. Nonetheless, for many patients, there comes a time when pain wins, and the suffering becomes inevitable. For those patients, the only alternative may be the ingestion of enough medication to permanently end the pain. The fact that most suicide attempts are unsuccessful ${ }^{4}$ indicates that people need help determining the correct dosage of medicine to consume in order to commit suicide. As experts in palliative care and medication, it is logical for that assistance to come from physicians.

After Carnegie-Mellon computer science Professor Randy Pausch was diagnosed with terminal pancreatic cancer, he gave an inspirational last lecture to his class. Prior to his death, Professor Pausch wrote a book based on his lecture. ${ }^{5}$ The book serves as a legacy for his wife and three small children. Professor Pausch tolerated the pain so he could spend his last days with his family. But thousands of terminally ill patients do not want to emulate Professor Pausch; those persons search for a way out of an existence filled with constant pain and hopelessness.

One way for these persons to make a graceful exit is physicianfacilitated suicide. Currently, physician-facilitated suicide is available only in three states: Montana, Oregon, and Washington. But even in

\footnotetext{
2 Thus, in this Article, I will not use the terms "physician-assisted suicide" or "physician-aided death." Instead, I will refer to the process as "physician-facilitated suicide."

3 This is most likely a Zen Buddhist aphorism. See, e.g., Mike Young, Pain is Inevitable. Suffering is Optional (Zen Aphorism), ZEN FOR THE REST OF US, http://www.zenfortherestofus.com/pain.html (last revised July 31, 2009).

4 Andrew J. McClurg, The Public Health Case For the Safe Storage of Firearms: Adolescent Suicides Add One More "Smoking Gun," 51 HASTINGS L.J. 953, 963-64 (2000).

5 RANDY PAUSCH WITH JEFFERY ZASLOW, THE LAST LECTURE (2008).
} 
those states, some patients are denied the opportunity to exit gracefully. I begin with a brief description of two such patients.

\section{A. Mary and Anna ${ }^{6}$}

Mary celebrated her fortieth birthday by hang gliding off a cliff. A few months later, doctors diagnosed Mary with stomach cancer. Mary's cancer was deadly, but slow acting. It was like a hurricane that hits land and stays over a small area for hours. The damage is overwhelming, but not quick. The doctors treated Mary's cancer with chemotherapy, radiation, and surgery, but the cancer continued to ravage her body. Finally, Mary refused any further treatment and went home. Doctors told Mary that she had about a year to live.

Despite her comfort care, Mary was never comfortable. She was in constant pain. Medication dulled the pain, but never totally eliminated it. Mary signed a "do not resuscitate" (DNR) form, but her heart refused to stop beating. During the progression of the disease, Mary's pain intensified. Mary slowly lost her voice. She possessed the physical capacity to speak, but her pain made it too hard to form a thought and articulate it. After about seven months, Mary's body finally gave out, and she was pronounced dead.

Anna was married to Steve, the love of her life, for almost fortyseven years until he died. About five years after Steve's death, doctors diagnosed Anna with Alzheimer's disease. After Anna's children could no longer care for her, they placed her in a long-term care facility. Anna had good days when her memory was clear. On those days, she engaged in pleasant conversation. On her bad days, Anna screamed and cried for no apparent reason. Anna got thinner and became terrified of everything and everybody.

Eventually, Anna's bad days out numbered her good days. The facility personnel restrained Anna when she started spitting, scratching, and fighting the members of the staff. The disease stole Anna's memories and her personality. It robbed Anna's children, Alice and Clinton, of their mother. They watched in horror as Anna died in stages. Anna remained in that condition for almost twenty

6 These stories were conveyed to me during my practice as a probate attorney. In order to maintain confidentiality, I have not used the subjects' full names and have declined to provide a citation. 
years before her body finally died. By that time, Anna's children had already progressed through all the stages of grief.

Doctors provided Mary and Anna with the best available medical care. Yet, they still suffered horribly. Under the current legal regime, neither Mary nor Anna would be entitled to the option of physicianfacilitated suicide. Only three states permit physicians to provide the knowledge and or means by which a patient can commit suicide. ${ }^{8}$ Two of those states, Oregon and Washington, authorize physicianfacilitated suicide by statute. ${ }^{9}$ Although Mary suffered from an incurable, irreversible physical condition, she would not be eligible to take advantage of the statutory provisions of either Oregon or Washington because she did not have a "terminal disease" within the meaning of those statutes. ${ }^{10}$ Mary did not qualify for terminally ill status because doctors predicted that she had more than six months to live. Anna would not have been a candidate for physician-facilitated suicide because she was physically healthy. It was only her mind that was dying slowly.

Is it ethical to refuse these women the chance to make a graceful exit? In a state with physician-facilitated suicide, shouldn't these women have that option?

\section{B. Exiting Gracefully}

In the United States, the law recognizes that a person has the right to refuse medical treatment. ${ }^{11}$ That right exists even if the refusal of medical treatment will lead to death. ${ }^{12}$ Recently, the mother of one of my friends needed emergency surgery to remove her stomach after a ruptured tumor caused severe internal bleeding. The eighty-one-yearold woman calmly told her doctors that she was going to leave the world with all of her body parts intact. Consequently, the doctors

\footnotetext{
${ }^{7}$ Mental health experts commonly define the five stages of grief as denial, anger, bargaining, depression and acceptance. ELISABETH KÜBLER-ROSS, ON DEATH AND DYING (13th prtg. 1978); see also Andrew J. McClurg, Dead Sorrow: A Story About Loss and a New Theory of Wrongful Death Damages, 85 B.U. L. REV. 1, 15 (2005).

8 Those states are Montana, Oregon, and Washington.

9 See discussion infra Part I.

10 OR. Rev. StAT. § 127.800(12) (2011); WASH. REV. CODE ANN. § 70.245.010(13) (West 2011).

11 See, e.g., Cruzan v. Dir., Mo. Dep’t of Health, 497 U.S. 261 (1990); In re Quinlan, 355 A.2d 647 (N.J. 1976); Elizabeth Helene Adamson, The Right to Refuse Life Sustaining Medical Treatment and the Noncompetent Nonterminally Ill Patient: An Analysis of Abridgment and Anarchy, 17 PEPP. L. REV. 461, 467-72 (1990).

12 Adamson, supra note 11, at 466.
} 
watched passively as she died, attempting to make her comfortable until her last breath. But even as she complained of being tired of suffering, the doctors' only option was to increase her pain medication. If her doctors took a more active role in my friend's mother's death, they might have been prosecuted for murder. Active euthanasia is not legal in any jurisdiction in the United States.

There are two types of euthanasia: passive and active. Passive euthanasia occurs when the doctor omits treatment and permits the patient to succumb to the disease; active euthanasia refers to when the doctor takes step to end the patient's life. ${ }^{13}$ In my friend's mother's case, the doctor honored the patient's request for passive euthanasia.

If Dr. Jack Kevorkian had his way, however, this story would be different. According to Dr. Kevorkian, an advocate for active euthanasia and a primary figure in the aid-in-dying movement, dying and suffering patients deserve the right to die with dignity. To achieve that goal, Kevorkian advocated that physicians be allowed to actively assist patients who wanted help dying. ${ }^{14}$ But even legislators in the jurisdictions that have legalized physician-facilitated suicide have refused to go as far as Kevorkian recommended. ${ }^{15}$ As opposed to euthanasia, physician-facilitated suicide occurs when a licensed physician supplies lethal medication to a patient so that the patient can use the medication to end his or her own life. ${ }^{16}$ Currently, in Oregon and Washington, physicians can provide the means for the patients to end their lives, but they cannot administer the lethal medication. ${ }^{17}$

The purpose of this Article is not to debate whether physicianfacilitated suicide or even euthanasia should be legal. Rather, my objective is to focus on how the states that have legalized the practice can ensure that it is properly regulated and available to those persons

13 Samuel I. Greenberg, Euthanasia And Assisted Suicide: Psychosocial ISSUES 18 (1997).

14 Cyril H. Wecht, The Right to Die and Physician-Assisted Suicide: Medical, Legal and Ethical Aspects (Part II), 17 MED. \& L. 581, 590-92 (1998).

15 Cyndi Bollman, Comment, A Dignified Death? Don't Forget About the Physically Disabled and Those Not Terminally Ill: An Analysis of Physician-Assisted Suicide Laws, 34 S. ILL. U. L.J. 395, 395 (2010).

16 Kathy L. Cerminara \& Alina Perez, Therapeutic Death: A Look At Oregon's Law, 6 PSYCHOL., PUB. POL'Y, \& L. 503, 506 (2000).

17 See Glen R. McMurry, Comment, An Unconstitutional Death: The Oregon Death With Dignity Act's Prohibition Against Self-Administered Lethal Injection, 32 U. DAYTON L. REV. 441, 443-44 (2007) (discussing the proposition as seen in Oregon's Act). 
who want it. ${ }^{18}$ To achieve that goal, I must address some of the concerns of opponents of physician-facilitated suicide.

In Part I, I describe the applicable laws in Washington, Oregon, and Montana. I discuss the legal landscape in Montana to show that, even if the legislature does not legalize physician-facilitated suicide, the court may step in to permit a suffering person to exit gracefully. In Part II, I examine the manner in which the Oregon and Washington statutes address some of the main concerns raised by opponents of physician-facilitated suicide. I also note some of the concerns that the statutes do not address.

Finally, in Part III, I explore ways in which the application of the statutes may be expanded to make physician-facilitated suicide available to people like Mary and Anna so they can exit gracefully. I make two primary recommendations. After receiving the lethal medication from their physicians, in some cases, patients should be able to request help to take the medication from non-medical personnel, including friends and family. ${ }^{19}$ Moreover, legislatures and courts should recognize that the traditional definition of "terminal" is not adequate to meet the needs of all persons desiring to exit gracefully. With these changes in place, courts and legislatures may begin to truly effectuate the interests underlying physician-facilitated suicide.

\section{LEGALIZING THE USE OF PHYSICIAN-FACILITATED SUICIDE}

The law recognizes that people have the right to refuse medical treatment. ${ }^{20}$ Because a majority of states no longer criminalize suicide, people in most states also have the right to take their own lives. ${ }^{21}$ However, the right to physician-facilitated suicide is not a fundamental right. ${ }^{22}$ Therefore, states have the authority to make the

\footnotetext{
18 This Article is a part of a larger writing project that I will work on as a visiting researcher at the Brocher Foundation in Geneva, Switzerland.

19 This practice is permissible in Switzerland because the person assisting does not have to be a physician. Thus, most of the facilitated suicides are performed by volunteers working for non-governmental organizations. See Rohith Srinivas, Comment, Exploring the Potential for American Death Tourism, 13 Mich. ST. J. MED. \& L. 91, 106 (2009).

20 See supra note 11.

21 Rebecca C. Morgan, Thomas C. Marks, Jr. \& Barbara Harty-Golder, The Issue of Personal Choice: The Competent Incurable Patient and the Right to Commit Suicide?, 57 MO. L. REV. 1, 9-10 (1992).

22 Washington v. Glucksberg, 521 U.S. 702 (1997) (holding that the right to receive help to commit suicide is not a fundamental liberty interest that is protected by the federal
} 
procedure illegal. ${ }^{23}$ The legislatures in the majority of states have enacted legislation making physician-assisted suicide illegal. ${ }^{24}$ As mentioned previously, only three states make it possible for suffering people to receive aid to die. ${ }^{25}$ In this section, I provide an overview of the law in those states. In the next section, I analyze the statutory provisions of the Oregon and Washington physician-facilitated suicide statutes.

\section{A. Enabling Physician-Facilitated Suicide Through Judicial Interpretation}

Most courts defer to the legislatures to resolve disputes involving physician-facilitated suicide. If no dispositive statute exists, courts evaluate the legal issues surrounding physician-facilitated suicide on a case-by-case basis. In at least one state, Montana, this has meant that a court can vindicate doctors who lend aid to terminally ill patients. If courts prevent states from prosecuting physicians who facilitate suicide, physicians may be more willing to provide life-ending support to patients. This would permit more suffering patients to avail themselves of physician-facilitated suicide.

In Baxter $v$. State, the Montana Supreme Court ruled that physician-assisted suicide ${ }^{26}$ is not against the public policy of the state. ${ }^{27}$ Retired truck driver Robert Baxter suffered from lymphocytic leukemia. ${ }^{28}$ Even though doctors treated Baxter with multiple rounds of chemotherapy, they did not expect him to survive the cancer. ${ }^{29}$ The combination of cancer and chemotherapy caused Baxter to experience

due process clause). The right to refuse medical treatment does not lead to the right to assisted suicide. Thus, a state can make the assisted suicide illegal without violating the Equal Protection Clause. Vacco v. Quill, 521 U.S. 793 (1997).

23 See Krischer v. McIver, 697 So. 2d 97, 100 (Fla. 1997) (discussing how Florida's ban on assisted suicide is supported by U.S. Supreme Court decisions in Washington and Vacco).

24 Sampson v. State, 31 P.3d 88, 91 (Alaska 2001). Alaska’s statute criminalizing assisted suicide reads, "A person commits the crime of manslaughter if the person intentionally aids another person to commit suicide ....” Id. (citing ALASKA STAT. ANN. 11.41.120(a)(2) (West, Westlaw through 2012 2d Reg. Sess. \& 3d Spec Sess.)).

25 See Shelly A. Cassity, Note, To Die or Not to Die: The History and Future of Assisted Suicide Laws in the U.S., 2009 UTAH L. REV. 515, 522.

${ }^{26}$ In this section, I am using the term "physician-assisted suicide" to remain consistent with the language used by the Baxter court.

27 Baxter v. State, 224 P.3d 1211, 1222 (Mont. 2009).

${ }^{28}$ Id. at 1214.

${ }^{29} \mathrm{Id}$. 
debilitating symptoms and to endure constant pain. ${ }^{30}$ Because doctors informed Baxter that his condition would get progressively worse, he sought help from his physician to end his life. ${ }^{31}$ Specifically, Baxter wanted his doctor to give him a lethal dose of prescription medication that he could take when he was ready to die. ${ }^{32}$

At the time, Montana prosecutors applied the state's homicide statutes against doctors who assisted in suicide. ${ }^{33}$ Baxter filed a lawsuit claiming that the application of the homicide statutes to cases involving physician-assisted suicide was unconstitutional. ${ }^{34}$ Four physicians and a nonprofit organization, Compassion \& Choices, joined Baxter in the suit. ${ }^{35}$ The District Court ruled in Baxter's favor, reasoning that the privacy and dignity clauses of the Montana Constitution gave a person the right to die with dignity. ${ }^{36}$ Part of that right was the right to receive help from a physician. ${ }^{37}$ To protect patients' right to physician-assisted suicide, the court ordered the State to refrain from prosecuting doctors who helped terminally ill patients die with dignity. ${ }^{38}$

The State appealed the case to the Montana Supreme Court. ${ }^{39}$ Deciding to resolve the issue on a consent theory rather than on constitutional grounds, the court held that physicians who assist in suicides could use the consent defense to avoid prosecution for homicide because physician-assisted suicide was not contrary to the public policy of the state. ${ }^{40}$ The court reasoned that physician-assisted suicide did not constitute "violent, peace-breaching conduct" that endangered the lives of others, ${ }^{41}$ nor did it violate any state laws. ${ }^{42}$

The court opined that a physician who helped a person commit suicide did not violate the state's homicide statute. ${ }^{43}$ Under the statute, to be guilty of homicide, a person must "purposely or
$30 \mathrm{Id}$.
${ }^{31} \mathrm{Id}$.
$32 \mathrm{Id}$.
33 Id.
34 Id.
$35 I d$.
36 Id.
${ }^{37} \mathrm{Id}$.
38 Id.
39 Id.
40 Id. 1222.
41 Id. at 1216.
42 Id. at 1217 .
43 Id. 
knowingly” cause another person's death. ${ }^{44}$ The physician's role was limited to providing the terminally ill patient with the means to end his or her life. Hence, because the physician did not force the patient to take the medication, the person's death was not a direct result of the physician's actions, nor did the physician's conduct amount to any other crime. In Montana, it is not a crime to commit suicide. Therefore, by providing the lethal medication, the physician was not aiding in the commission of a crime. ${ }^{45}$

Lastly, the Montana Supreme Court stated that physician-assisted suicide did not violate the provisions of the Terminally Ill Act. ${ }^{46}$ That Act gives doctors who comply with patients' requests to withhold or withdraw life-sustaining treatment immunity from criminal and civil liability. ${ }^{47}$ By immunizing the physicians' conduct, the legislature indicated that it was in the public's interest to permit patients to refuse medical treatment even if that refusal will result in death. Furthermore, nothing in the Act indicated that physicians cannot go a step further and provide patients with the means to end their lives. ${ }^{48} \mathrm{~A}$ physician who withdraws medical care is directly involved in the death of the patient. By contrast, a physician who supplies the patient with the means to end his or her life is only indirectly involved in the patient's death. ${ }^{49}$ As a result, the court concluded that if direct physician assistance was not against public policy, neither was indirect physician assistance. $^{50}$

The legislature's intent in enacting the Terminally Ill Act was to ensure that a terminally ill patient was given the opportunity to choose the time and manner of his or her death. ${ }^{51}$ Permitting physician-assisted suicide will help to carry out that intent. Thus, the court held that it was not against public policy for a physician who assisted in a suicide to use consent as a defense to a homicide charge. $^{52}$

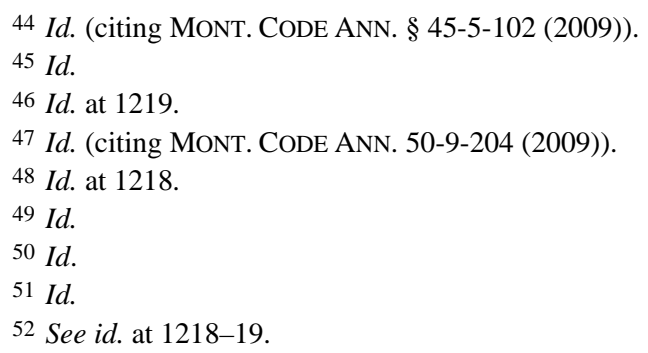


As a consequence of the Baxter decision, terminally ill patients in Montana may receive assistance to die from willing physicians. However, nothing in the decision prevents the legislature from banning the practice in the state. Consequently, Montana residents are forced to live with uncertainty when it comes to the availability of physician-facilitated suicide. That uncertainty may discourage suffering persons from seeking assistance to end their lives. A dying person may not have the time or energy to engage in a court battle. Persons living in states that statutorily permit the practice are in a better position to exit gracefully because there are mechanisms in place for them to receive aid in dying.

\section{B. Legalizing Physician-Facilitated Suicide Through Legislative Action}

In passing the Oregon Death With Dignity Act in late 1997, Oregon became the first state to make physician-facilitated suicide legal by statute. ${ }^{53}$ Washington enacted its own Death With Dignity Act in the fall of $2008 ;{ }^{54}$ the provisions of the statutes are similar. Under both, a capable, terminally ill adult resident may request a prescription for lethal medication from a physician. ${ }^{55}$ After acquiring the medication, the person can ingest it if and when he or she so desires. The statutes focus upon the person's capacity to request the medication and the person's adherence to the procedures necessary to request the medicine. To be eligible to receive the lethal medicine, the person must meet the conditions set forth in the statutes and follow the procedures mandated by the statutes.

\section{Necessary Characteristics of the Patient}

Patients' eligibility for physician-facilitated suicide depends on meeting specified criteria. First, patients must be residents of the states. $^{56}$ To be considered a resident, the patient must show a connection to the state. It is not difficult for patients to meet the

53 See generally Katherine A. Chamberlain, Note, Looking For A "Good Death": The Elderly Terminally Ill's Right to Die by Physician-Assisted Suicide, 17 ELDER L.J. 61, 85 (2009).

54 Kathryn L. Tucker, The Campaign to Deny Terminally Ill Patients Information and Choices at the End of Life, 30 J. LEGAL MED. 495, 502 (2009).

55 OR. ReV. STAT. § 127.805 (2011); WASH. ReV. CodE ANN § 70.245.020 (West 2011).

56 OR. Rev. StAT. § 127.860 (2011); WASH. REV. CODE ANN. § 70.245.130 (West 2011). 
residency requirement. Acceptable forms of proof include: (1) a state driver's license, (2) a state voter's registration card, (3) ownership or rental of real estate in the state, or (4) a recent state income tax return. ${ }^{57}$ In addition, the statutes require that the patient seeking the lethal medication has a terminal disease, which in turn is defined as a disease that is "incurable and irreversible."58 Furthermore, under the statute, a terminal disease must mean that doctors expect the person to die within six months of the diagnosis. ${ }^{59}$

In addition, the patient must be able to make health care decisions and communicate them to the appropriate medical personnel. ${ }^{60}$ Prior to requesting the medication, the patient need not undergo counseling. ${ }^{61}$ However, a patient who is deemed to be suffering from a psychiatric or psychological disorder or depression causing impaired judgment must go through counseling to be considered competent to receive the lethal medication. ${ }^{62}$ The requirement of mental competency does not apply to the rescission of the request to receive the lethal medication. ${ }^{63}$ As a result, a mentally incompetent patient may change his or her mind and withdraw his or her request for the medication.

57 OR. REv. StAT. § 127.860 (2011); WASH. REV. CODE ANN. § 70.245.130 (West 2011).

58 OR. REV. STAT. § 127.800(12) (2011); WASH. REV. CODE ANN. § 70.245.010(13) (West 2011).

59 OR. REV. STAT. § 127.800(12) (2011); WASH. REV. CODE ANN. § 70.245.010(13) (West 2011).

60 OR. REV. STAT. § 127.800(3) (2011) (“'CCapable’ means that in the opinion of a court or in the opinion of the patient's attending physician or consulting physician, psychiatrist or psychologist, a patient has the ability to make and communicate health care decisions to health care providers, including communication through persons familiar with the patient's manner of communicating if those persons are available.”). The Washington statute uses the term "competent” instead of capable. WASH. REV. CODE ANN. § 70.245.010(3) (West 2011) ("'Competent' means that, in the opinion of a court or in the opinion of the patient's attending physician or consulting physician, psychiatrist, or psychologist, a patient has the ability to make and communicate an informed decision to health care providers, including communication through persons familiar with the patient's manner of communicating if those persons are available.”).

61 Herbert Hendin, Kathleen Foley, \& Margot White, Physician-Assisted Suicide: Reflections on Oregon's First Case, 14 IssuEs L. \& MED. 243, 251 (1998).

62 OR. Rev. StAT. § 127.825 (2011); WASH. Rev. CodE. AnN. § 70.245.060 (West 2011).

63 OR. Rev. StAT. § 127.845 (2011); WASH. ReV. Code AnN. § 70.245.100 (West 2011). 


\section{2. $\quad$ The Mandated Procedures}

Patients deemed eligible to make the request must follow the procedure set forth in the statutes. Traditionally, when the law sets forth requirements for a person to make a life-changing decision, the execution process is rigid. For instance, a person making a will must usually have it signed, witnessed and/or acknowledged. ${ }^{64}$ The Oregon and Washington statutes require the patient seeking life-ending medication to follow a set procedure; the mandated process is actually similar to the will execution process.

After the patient meets the initial statutory capacity mandates, the patient's decision to request the lethal medication must be informed, and the request must be executed in conformance with the statutory requirements. ${ }^{65}$ The patient cannot make an informed decision unless the physician makes sure that the patient understands the medical diagnosis and prognosis; the potential risks and probable results of taking the medication; ${ }^{66}$ and the other available options including comfort care, hospice care and pain control. ${ }^{67}$ This informed consent is similar to the consent a patient has to give before a physician can perform a medical procedure on the patient. ${ }^{68}$ The purpose is to ensure that the patient has all of the relevant facts before making the decision to request the lethal medication. ${ }^{69}$

The patient must also sign and date the written request for the medication. In the patient's presence, at least two persons must attest that "to the best of their knowledge and belief the patient is capable, acting voluntarily, and is not being coerced to sign the request." ${ }^{, 70}$ The law restricts the pool of persons who can serve as witnesses to protect the interests of the patient. Thus, one of the witnesses must be

64 See Joseph Karl Grant, Shattering and Moving Beyond the Gutenberg Paradigm: The Dawn of the Electronic Will, 42 U. MICH. J.L. REFORM 105, 118 (2008).

65 OR. REV. STAT. § 127.830 (2011); WASH. REV. CODE ANN. § 70.245.070 (West 2011).

66 Some patients have survived after taking the lethal drugs for days or months. Other patients have regurgitated the medication.

67 OR. Rev. Stat. § 127.815(1)(c)(A)-(E) (2011); WAsh. ReV. Code AnN. § 70.245.010(7)(a)-(e) (West 2011).

68 See Jennifer Y. Seo, Raising the Standard of Abortion Informed Consent: Lessons to Be Learned From the Ethical and Legal Requirements for Consent to Medical Experimentation, 21 COLUM. J. GENDER \& L. 357, 357 (2011) ("[A]ll states require informed consent before medical procedures either by statute or case law.”).

69 Nadia N. Sawicki, The Abortion Informed Consent Debate: More Light, Less Heat, 21 CORNELL J.L. \& PUB. POL'Y, 1, 13 (2011).

70 OR. REV. STAT. § 127.810 (2011); WASH. REv. CODE ANN. § 70.245.030(1) (West 2011). 
disinterested. ${ }^{71}$ Further, the doctor caring for the patient is not permitted to act as a witness to the request. ${ }^{72}$ Nevertheless, when the patient is a resident of a long-term care facility, one of the witnesses must be a person designated by the facility. ${ }^{73}$ After the request is made, another physician must examine the patient's medical records to confirm the diagnosis. $^{74}$

Oregon and Washington have attempted to regulate the use of physician-facilitated suicide in a manner that protects the rights of patients and the interests of physicians. Patients are given the opportunity to choose to exit gracefully. The statutory requirements ensure that a patient's choice to obtain the lethal medication is voluntary and that the patient can change his or her mind at any time. The rights of the patient are further protected by the existence of a waiting period ${ }^{75}$ and reporting requirements. ${ }^{76}$ The statutes protect physicians from civil and criminal liability. ${ }^{77}$ By enacting the statutes, the legislatures attempted to address several key concerns raised by the opponents of legalized physician-facilitated suicide.

\footnotetext{
71 In order to be considered disinterested, the person must not be: “(a) A relative of the patient by blood, marriage or adoption; (b) a person who at the time the request is signed would be entitled to any portion of the estate of the qualified patient upon death under any will or by operation of law; or (c) an owner, operator or employee of a health care facility where the qualified patient is receiving medical treatment or is a resident.” OR. REV. STAT. $\S 127.810$ (2)(a)-(c) (2011); WASH. REV. CODE ANN. § 70.245.030(2)(a)-(c) (West 2011).

72 OR. ReV. StAT. § 127.810(3) (2011); WASH. ReV. CodE ANN. § 70.245.030(3) (West 2011).

73 OR. Rev. Stat. § 127.810(4) (2011); WAsh. Rev. CODE AnN. § 70.245.030(4) (West 2011).

74 OR. ReV. Stat. § 127.820 (2011); WASH. ReV. Code AnN. § 70.245.050 (West 2011).

75 See OR. Rev. StAT. § 127.850 (2011); WASH. ReV. CodE ANN. § 70.245.110 (West 2011).

76 OR. Rev. STAT. § 127.865 (2011); WASH. ReV. CodE ANN. § 70.245.150 (West 2010).

77 OR. REv. STAT. § 127.885(1) (2011); WASH. REV. CODE ANN. § 70.245.190(1)(a) (West 2011).
} 
II

\section{REgulating the Use OF Physician-FACILITATED SUICIDE}

\section{A. Legislative Solutions to Common Concerns Over Physician- Facilitated Suicide}

Persons who think that physician-facilitated suicide should not be legal have expressed concerns about the safety of specific segments of the population. In particular, they fear that patients who are part of vulnerable populations will be disadvantaged by the existence of legal physician-facilitated suicide. ${ }^{78}$ This fear stems from the philosophy of eugenics, a movement devoted to improving the human species by controlling heredity. ${ }^{79}$ In addition, opponents of physician-facilitated suicide worry about physicians who may have a Kevorkian complex that leads them to think that all of their terminally ill patients are better off committing suicide. These persons were concerned that legalizing physician-facilitated suicide might make physicians more comfortable with euthanasia. ${ }^{80}$ Based upon their biases and prejudices, physicians may decide that some lives are more worthy or better lived than others. ${ }^{81}$ Instead of being considered a last resort option, doctors may see physician-facilitated suicide as the first treatment option for some terminally ill patients. ${ }^{82}$ When enacting physician-assisted suicide statutes, the legislatures of Oregon and Washington appeared to be mindful of the concerns expressed by those persons opposing the legislation.

\section{Targeting the Elderly and Disabled}

Persons opposing the legalization of physician-facilitated suicide have argued that, to reduce end-of-life costs, doctors may pressure the elderly and the disabled to request the lethal medication. ${ }^{83}$ Some

\footnotetext{
78 See M. Cathleen Kaveny, Managed Care, Assisted Suicide, and Vulnerable Populations, 73 NotRe DAME L. REV. 1275, 1304-07 (1998).

79 See Shoshana K. Kehoe, Giving the Disabled and Terminally Ill a Voice: Mandating Mediation For All Physician-Assisted Suicide, Withdrawal of Life Support, or LifeSustaining Treatment Requests, 20 HAMLINE J. PUB. L. \& POL'Y 373, 378 (1999).

80 See Katherine A. Chamberlain, Looking For a "Good Death": The Elderly Terminally Ill's Right to Die by Physician-Assisted Suicide, 17 ELDER L.J. 61, 83-85 (2009).

81 See infra Part II.A.1.

82 See Kelly Lyn Mitchell, Note, Physician-Assisted Suicide: A Survey of the Issues Surrounding Legalization, 74 N.D. L. REV. 341, 354-55 (1998).

83 See Anthony J. Dangelantonio, Physician-Assisted Suicide: The Legal and Practical Contours, 4 RISK-ISSUES IN HEALTH \& SAFETY 55, 60-61 (1993).
} 
opponents also fear that the elderly and the disabled may be targeted as candidates for physician-facilitated suicide based solely upon their age and infirmities. They contend that physicians may aggressively encourage terminally ill elderly or disabled patients to consider physician-facilitated suicide in cases where they would not do so with patients who are younger and/or able-bodied. ${ }^{84}$ Or given the lack of quality of life, some doctors may assume that those patients would want to request the lethal medicine. Bioethicist Wesley J. Smith contends that the elderly and the disabled are often made to feel like they have a duty to die so they will not be a burden on society and their families. ${ }^{8}$

The legislatures attempted to address these concerns. The statutes explicitly state that a patient's eligibility for physician-facilitated suicide cannot be based exclusively on his or her age or disability. ${ }^{86}$ Hence, those characteristics alone should not result in the presumption that the patient would want physician aid in dying. This clarification and other safeguards in the statutes reduce the chance that elderly and disabled patients will be sacrificed to save medical costs.

However, it is unclear if the language in this statute is sufficient to address the concerns put forth by opponents of physician-facilitated suicide. For the statutory preclusion to mean anything, doctors must be better educated about the needs of elderly and disabled patients and must be taught that those lives have value.

\section{Encouragement for Suicidal Persons}

Some persons feel that citizens who are already suicidal might perceive legalized physician-facilitated suicide as the state giving its stamp of approval to suicide. They opine that once the stigma is removed from suicide, the practice might become widespread because some persons may be persuaded to commit suicide. ${ }^{87}$ They fear that the availability of physician-facilitated suicide may encourage

${ }^{84}$ See, e.g., Jody B. Gabel, Release From Terminal Suffering?: The Impact of AIDS on Medically Assisted Suicide Legislation, 22 FLA. ST. U. L. REV. 369, 407-08 (1994).

85 Wesley J. SMith, ForCED EXIT: EuthanAsia, Assisted Suicide AND THE NEW DUTY TO DIE 14-16, 193-94 (2003).

86 OR. REV. STAT. § 127.805(2) (2011); WASH. REV. CODE ANN. § 70.245.020(2) (West 2011).

87 See Laura Trenaman-Molin, Comment, Physician-Assisted Suicide: Should Texas Be Different?, 33 Hous. L. REV. 1475, 1488-89 (1997) (arguing that a slippery slope will be created whereby vulnerable persons may be manipulated into suicide). 
terminally ill persons who are depressed to request the lethal medication instead of fighting the disease. ${ }^{88}$ This is a legitimate concern because the statutes do not require all patients to undergo counseling before they choose physician-facilitated suicide.

Currently, the law takes certain steps to prevent suicidal persons from taking their own lives. For instance, prisoners are placed on "suicide watch" if guards think that they are a danger to themselves. ${ }^{89}$ Ironically, prison guards take steps to prevent death row inmates from committing suicide. ${ }^{90}$ Authorities may also place persons who are suspected of being a danger to themselves and/or others on a seventytwo hour hold at a psychiatric facility. ${ }^{91}$

Members of the public are uncomfortable with the possibility of the state helping a suicidal person commit suicide. It is too much like "suicide by cop" where a person pulls a loaded gun in order to get a police officer to kill him or her. ${ }^{92}$ Some people even believe that it is unethical for the state to execute death row inmates who ask to die. ${ }^{93}$

The Oregon and Washington statutes attempt to deal with this issue by including several safeguards. If a health care professional thinks that the person is suffering from a mental illness or depression that impairs his or her judgment, the statutes require the physician to refer the person to counseling before providing the lethal medication. ${ }^{94}$ In addition, the person is permitted to rescind the request for the

88 See Eric Chevlen, The Limits of Prognostication, 35 DuQ. L. REV. 337, 346-49 (1996); James Bopp, Jr. \& Richard E. Coleson, The Constitutional Case Against Permitting Physician-Assisted Suicide For Competent Adults With "Terminal Conditions,” 11 Issues L. \& MED. 239, 243 (1995).

89 Nelson v. State, 916 A.2d 74, 84 (Conn. App. Ct. 2007).

90 Christopher J. Skinner, An Obligation to Live: Retaining the Cultural Meaning of Capital Punishment by Prohibiting Volunteerism On Death Row and the Implications of Its Continued Practice, 39 Lincoln L. REV. 55, 73-74 (2011).

91 Lynne N. Henderson, Note, “We're Only Trying to Help”: The Burden and Standard of Proof in Short-Term Civil Commitment, 31 STAN. L. REV. 425, 430-31 (1979).

92 See Rahi Azizi, When Individuals Seek Death at the Hands of the Police: The Legal and Policy Implications of Suicide by Cop and Why Police Officers Should Use Nonlethal Force in Dealing With Suicidal Suspects, 41 GOLDEN GATE U. L. REV. 183, 187-88 (2011).

${ }^{93}$ Cf. Kristen M. Dama, Comment, Redefining A Final Act: The Fourteenth Amendment and States' Obligation to Prevent Death Row Inmates From Volunteering to Be Put to Death, 9 U. PA. J. CONT. L. 1083 (2007) (discussing constitutionality of volunteerism).

94 OR. Rev. StAT. § 127.815(d)-(e) (2011); WASH. REV. CodE ANN. § 70.245.060 (West 2011). 
medication at any time. ${ }^{95}$ The statutes also mandate a waiting period between the request for the medication and the writing of the prescription, ${ }^{96}$ which allows the physician to make sure that the patient is capable of making an informed decision about committing suicide.

Depression and mental illness should not prevent a patient from choosing physician-facilitated suicide. However, to protect persons who are clinically depressed or mentally ill, the statutes should require the court to appoint a guardian to assist them in making the decision to request the lethal medication.

\section{Weeding Out Poor Patients and Patients of Color}

The existence of inequalities in health care has been a concern in the United States for decades. ${ }^{97}$ Consequently, it is not surprising that some people are concerned that poor people and people of color may be disadvantaged by the existence of physician-facilitated suicide. Instead of investing resources to treat certain patients, physicians may decide that it is more cost effective to just write a prescription. Terminally ill low-income patients and patients of color often do not receive the same level of treatment as their counterparts. ${ }^{98}$ When the New York legislature explored the possibility of legalizing physicianfacilitated suicide, this was a major concern of the members of the task force. To illustrate, the New York State Task Force on Life and the Law stated in its 1994 report on physician-assisted suicide and euthanasia:

The risk of harm is greatest for the many individuals in our society whose autonomy and well-being are already compromised by poverty, lack of access to good medical care, advanced age, or membership in a stigmatized social group. The risks of legalizing assisted suicide and euthanasia for these individuals, in a health care system and society that cannot effectively protect against the impact

95 OR. REV. STAT. § 127.845 (2011); WASH. REV. CODE ANN. § 70.245.100 (West 2011).

96 See OR. REV. STAT. § 127.850 (2011); WASH. REV. CODE ANN. § 70.245.110 (West 2011).

97 Erika Blacksher, Health Reform and Health Equity: Sharing Responsibility for Health in the United States, 39 HofSTRA L. REV. 41, 42-43 (2011).

98 Paul S. Kawai, Should the Right to Die be Protected? Physician Assisted Suicide and Its Potential Effect on Hawai'i, 19 U. HAW. L. REV. 783, 797-98 (1997). 
of inadequate resources and ingrained social disadvantages, would be extraordinary.

The members of the Task Force reasoned that if the law could not protect socially and economically disadvantaged persons from being given inadequate medical treatment, it could not protect them from abuses that might occur if physician-facilitated suicide was legalized.

The Oregon and Washington statutes do not specifically offer a solution to this perceived problem. Nonetheless, the concerns have been proven to be unfounded. ${ }^{100}$ The typical patient requesting physician-facilitated suicide in both states is white, married, college educated, and over the age of 65; the patient also has some kind of cancer, has private health insurance, is enrolled in hospice care, is concerned primarily about the loss of autonomy, and dies at home. ${ }^{101}$ Given the demographics of the persons requesting the lethal medication, it appears that the existence of physician-facilitated suicide has not unduly burdened poor people and people of color.

Nonetheless, it should be noted that the populations of Oregon and Washington are predominately white. Thus, the demographics of the patients requesting the medication may be different if physicianfacilitated suicide were available in a diverse state like California or Texas.

On the other hand, members of those populations may have a greater need for physician-facilitated suicide. Studies have shown that low-income people and people of color often receive inadequate pain treatment. ${ }^{102}$ Therefore, when they are diagnosed with terminal illnesses, members of those populations frequently are forced to tolerate significant pain. The availability of physician-facilitated suicide may offer them a way out of their horrible circumstances. However, low-income persons will probably not be able to afford to

99 N.Y. STATE DEP'T OF HEALTh, When DEATH IS SOUght: AsSisted SUICIDE AND EUTHANASIA IN THE MEDICAL CONTEXT 120 (1994), available at http://www.health.ny .gov/regulations/task_force/reports_publications/when_death_is_sought/.

100 Christin A. Batt, Comment, The Pain Relief Promotion Act of 1999 and PhysicianAssisted Suicide: A Call For Congressional Self-Restraint, 38 SAN DIEGO L. REV. 297, 305 (2001).

101 Or. Pub. Health DiV., Oregon's DeAth With Dignity ACt-2011 Summary 2 (2012), available at http://public.health.oregon.gov/ProviderPartnerResources/Evaluation Research/DeathwithDignityAct/Documents/year14.pdf.

102 See Vence L. Bonham, Race, Ethnicity, And Pain Treatment: Striving to Understand the Causes and Solutions to the Disparities in Pain Treatment, 29 J.L. MED. \& ETHICS 52 (2001); see also Yoel Goldfeder, Note, Assisted Suicide and the Illusory Poverty Component, 5 GeO. J. ON Fighting POVERTY 335, 336 (1998). 
take advantage of physician-facilitated suicide because the lethal medication is expensive and is usually not paid for by insurance.

\section{Overeager Physicians}

Some opponents of physician-facilitated suicide are concerned about the actions of physicians. They fear that, in an effort to ease the suffering of patients and to reduce medical costs, some physicians may be too eager to prescribe the lethal medicine. According to stories on the Internet and in the news, people living in the Netherlands "carry cards saying they do not want euthanasia." Recently, the media reported that clinics in the Netherlands offer mobile services for persons who want to die at home. ${ }^{104}$ Euthanasia and physician-facilitated suicide are legal and actively used in the Netherlands. ${ }^{105}$ Opponents of physician-facilitated suicide sometimes unfairly link the two practices. Thus, those persons are afraid that, if they suddenly become ill, doctors will consider facilitated suicide as just another treatment protocol. They maintain that, to save costs, physicians may encourage patients to request the lethal medication as soon as they are diagnosed with a terminal illness. Given the staggering costs of end-of-life care, this may be a valid concern. ${ }^{106}$

This argument may stem from the distrust that some people have of doctors. For example, some people refuse to carry organ donor cards because they are afraid that doctors will be more concerned about harvesting their organs than treating them. ${ }^{107}$

To avoid that possibility, the statutes have safeguards to ensure that patients are protected from overeager physicians. For instance, the patient must give written informed consent. ${ }^{108}$ The written request

103 Martin Beckford, Fearful Elderly People Carry 'Anti-Euthanasia Cards,' TELEGRAPH (Apr. 21, 2011, 11:30 PM), http://www.telegraph.co.uk/health/healthnews /8466996/Fearful-elderly-people-carry-anti-euthanasia-cards.html.

104 Ben Brumfield, Dutch Euthanasia Clinic Offers Mobile Service, CNN (Mar. 9, 2012, 6:57 AM), http://www.cnn.com/2012/03/07/world/europe/netherlands-euthanasia -clinic/index.html.

105 Kurt Darr, Physician-Assisted Suicide: Legal and Ethical Considerations, $40 \mathrm{~J}$. HEALTH L. 29, 50-51 (2007).

106 See Greer Donley \& Marion Danis, Making the Case For Talking to Patients About the Costs of End-of-Life Care, 39 J.L. MED. \& ETHICS 183, 184-85 (2011) (discussing the significant costs of healthcare incurred by terminally ill patients and their families).

107 Jay A. Friedman, Taking the Camel by the Nose: The Anencephalic as a Source for Pediatric Organ Transplants, 90 COLUM. L. REV. 917, 963 (1990).

108 OR. REV. STAT. § 127.805 (2011); WASH. REV. CODE ANN. § 70.245.020 (West 2011). 
form must be witnessed by independent parties. ${ }^{109}$ In addition, the patient cannot request the medication without being examined by at least two physicians - the doctor who diagnoses the illness and the doctor who confirms it. ${ }^{110}$ Perhaps most importantly, because the patient must take the medication without assistance, the physician's role in the process is limited. Thus, the physician does not have the option of euthanizing the terminally ill patient.

\section{The Floodgates}

According to some people, the availability of physician-facilitated suicide may open the floodgates for people who normally would not consider suicide to start committing suicide. Those people raise the specter of a "Jim Jones" kind of mass suicide movement. ${ }^{111}$ They fear that, instead of taking advantage of comfort care or hospice care, terminally ill patients will choose to take the lethal medication. The fear is that some patients who have the possibility of going into remission may miss that chance because they select physicianfacilitated suicide too early in the process. ${ }^{112}$

The statutory reporting requirements will help to safeguard against this happening. ${ }^{113}$ Both statutes require annual reporting of patients requesting the lethal medication. Thus, the appropriate state agency will be able to monitor the trend of patients taking the medicine.

Reports indicate that Oregon and Washington are a long way from widespread physician-facilitated suicide. ${ }^{114}$ For instance, in Oregon, annual reports show that between 1998 and 2010, only 525 patients died from ingesting the medicine. ${ }^{115}$ Every patient requesting the

109 OR. REV. STAT. § 127.810 (2011); WASH. REV. CODE ANN. § 70.245.030 (West 2011).

110 OR. REV. STAT. § 127.820 (2011); WASH. REV. CODE ANN. § 70.245.050 (West 2011).

111 Jim Persels, Comment, Forcing the Issue of Physician-Assisted Suicide. Impact of the Kevorkian Case on the Euthanasia Debate, 14 J. LEgAL MED. 93, 120 n.201 (1993), available at Westlaw.

112 See Steve Perlmutter, Physician-Assisted Suicide-A Medicolegal Inquiry, 15 MicH. ST. U. J. MED. \& L. 203, 218-21 (2011).

113 See Andrew I. Batavia, So Far So Good: Observations on the First Year of Oregon's Death With Dignity Act, 6 PsYCHOL. PUB. POL'Y \& L. 291, $294-95$ (June 2009).

114 The 2011 Oregon Death With Dignity Report indicates that in the fourteen-year history of implementation physicians have written 935 prescriptions and 596 people have ingested the medication. OR. PUB. HEALTH DiV., supra note 102, at 2.

115 Or. Pub. Health Div., OREgon's DeAth With Dignity ACT-2010 SuMmary 2 (2011), available at http://public.health.oregon.gov/ProviderPartnerResources/Evaluation Research/DeathwithDignityAct/Documents/year13.pdf. 
lethal medicine did not take it. To illustrate, in Washington, in 2010, only 51 of the 87 persons who requested the medicine died after ingesting it. ${ }^{116}$ These data suggest that some terminally ill persons requested the medication not because they wanted to commit suicide, but because they were comforted by having the ability to do so if their suffering became unbearable. As part of the legalization and regulation of physician-facilitated suicide, legislatures in Oregon and Washington tried to alleviate some of the most commonly raised concerns. However, the legislatures need to amend the statutes to deal with other potential problems.

\section{B. Issues Yet to be Resolved by the Legislature}

\section{Death Tourism}

A number of newspaper articles and a few documentaries have focused upon international "death tourism."117 International death tourism occurs when U.S. citizens go to places like Switzerland ${ }^{118}$ and the Netherlands to receive lethal medication to commit suicide. ${ }^{119}$ Similarly, domestic "death tourism" would happen when patients from other states go to Oregon or Washington to obtain the right to physician-facilitated suicide. ${ }^{120}$ Given the ease in which persons can travel from state to state, domestic death tourism may become a problem. Death tourism will make it difficult for the state to monitor the use and distribution of the lethal medication. It also undermines the public policy of states that have chosen to make physicianfacilitated suicide illegal.

116 Wash. State Dep’T of HeAlth, 2010 DeAth With Dignity Act Report 1 (2011), available at http://www.doh.wa.gov/portals/1/Documents/5300/DWDA2010.pdf.

117 See, e.g., Susan Donaldson James, Tourists Trek to Mexico for 'Death in a Bottle', ABC News (July 31, 2008), http://abcnews.go.com/Health/MindMoodNews/story?id $=5481482$ \&page $=1 \&$ singlePage $=$ true\#.UHxXwUKSPjQ; Cecilia Rodriguez, Holland Targets Its Drugs-and-Death Tourism, FoRBES (Apr. 4, 2012, 7:29 PM), http://www .forbes.com/sites/ceciliarodriguez/2012/04/04/holland-targets-its-drugs-and-death -tourism/.

118 In Switzerland, only one organization, Dignitas, facilitates the death of non-Swiss residents. Alexander R. Safyan, Note, A Call for International Regulation of the Thriving “Industry” of Death Tourism, 33 LOY. L.A. INT'L \& COMP. L. REV. 287, 311 (2011).

119 Diana Hassel, Sex and Death: Lawrence's Liberty and Physician-Assisted Suicide, 9 U. PA. J. CONST. L. 1003, 1024-25 (2007).

120 See Brian H. Bix, Physician-Assisted Suicide and Federalism, 17 NOTRE DAME J.L. ETHICS \& PUB. POL’y 53, 60 (2003). 
The legislatures have taken limited steps to discourage domestic death tourism; for example, by making residency in the respective state a requirement. ${ }^{121}$ However, the residency requirements are inadequate to discourage terminally ill persons from travelling to those states to obtain the lethal medication. We live in a mobile society, so it is easy for persons to travel from state to state. In addition, it is not complicated for persons to establish state residency. Under both the Oregon and Washington statutes, it is easy and inexpensive for persons to become residents.

Furthermore, nothing in the statutes requires patients to take the medication in the state. Patients can obtain the medication in Oregon or Washington and take it elsewhere. Opponents of physicianfacilitated suicide fear that this may make it difficult for the state agencies to monitor the use and abuse of the medication. The physician is not required to be in attendance when the medicine is taken and the annual reports show that a significant percentage of the cases involved patients taking the lethal medication without the presence of physicians. ${ }^{122}$ Unlike in the Netherlands, nothing in the Oregon and Washington statutes mandates that the physician has a long-standing relationship with the patient prior to writing the prescription for the lethal medication.

To resolve this issue, the legislatures should strengthen the residency requirements. For example, the person could be required to stay in the state for a certain number of days before having the right to obtain the documents that make him or her a resident of the state for purposes of requesting the lethal medication. This is the procedure in place for obtaining benefits that states reserve for their citizens like marriage licenses, in-state tuition, and welfare benefits. By limiting the potential patients eligible to obtain the medication to the true residents of the states, the legislatures may be better able to protect the patients from abuse.

\section{Unused Medication}

According to some opponents of physician-facilitated suicide, a practice just as dangerous as domestic "death tourism" may be the distribution of the medication to people other than the patient. ${ }^{123}$ The

121 See Nicholas P. Terry, Under-Regulated Health Care Phenomena in a Flat World: Medical Tourism and Outsourcing, 29 W. NEW ENG. L. REV. 421, 433 (2007).

122 See, e.g., WASH. StATE DeP'T OF HEALTH, supra note 117, at 9.

123 Cf. Marilyn Golden \& Tyler Zoanni, Killing Us Softly: The Dangers of Legalizing Assisted Suicide, 3 DisabiLity \& HEALTH J. 16, 25 (2010) (discussing flaws in reporting 
statutes do not prevent persons from giving or selling unused medication to other persons. While the Washington statute requires that the unused medication be discarded in a lawful manner, ${ }^{124}$ no mechanism exists to monitor what happens to the medication after it is dispensed. The 2010 Washington Report indicated that there was evidence that only fifty-one people died after ingesting the medication during that year out of the eighty-seven to whom it was dispensed. ${ }^{125}$ Further, the 2011 Oregon Death With Dignity Act Report stated that 114 patients received prescriptions for legal medication, but only 71 persons died from ingesting the medication. Hence, the medication obtained by the remaining people was either unaccounted for or unused.

As the number of patients requesting physician-facilitated suicide increases, this may become a major problem. Currently, teenagers routinely raid their parents' medical cabinets looking for a quick high. A dangerous new activity is the "pharm party" where teenagers and young adults toss different pills into a bowl and pass it around so they can take a random selection of pills to get high. ${ }^{126}$ If some of the unused lethal medication ended up in one of those bowls, it would be a major tragedy.

A possible resolution to this problem is to assign a social worker to the person electing physician-facilitated suicide. That person could be responsible for following up to determine if and when the persons ingested the lethal medication. If the medication is not ingested within a reasonable period of time, the patient would be required to return the medication to a central location so it could be destroyed.

Another option is to track the lethal medication through a prescription drug monitoring program (PMP). ${ }^{127}$ Currently, forty-one

and observing that "[n]o one knows what happens to lethal agents that are not used by patients who originally request them"), available at http://download.journals .elsevierhealth.com/pdfs/journals/1936-6574/PIIS1936657409000739.pdf.

124 WASH. REV. CODE ANN. § 70.245.140 (West 2011).

125 WASH STATE DEP'T OF HEALTH, supra note 117, at 1.

126 Monica Kim Sham, Note, Down On the Pharm: The Juvenile Prescription Drug Abuse Epidemic and the Necessity of Holding Parents Criminally Liable For Making Drugs Accessible in Their Homes, 27 J. Contemp. Health L. \& POL'y 426, 436-37 (2011).

127 According to the National Alliance for Model State Drug Laws (NAMSDL), a PMP is a statewide electronic database which collects designated data on substances dispensed in the state. MODEL PRESCRIPTION Monitoring PROGRAM (PMP) ACT (Nat'l Alliance for Model State Drug Laws 2011), available at http://www.namsdl.org/documents /ModelPMPAct111911withoutcommentary_001.pdf. 
states have agencies set up to monitor the distribution of prescription drugs. ${ }^{128}$ Oregon recently created such a program, ${ }^{129}$ and while Washington has not yet done so, it could do so easily. The lethal medication can be labeled and given a tracking number. The patient's estate could face a penalty if the unused medication is not returned to the state agency for disposal. Because the physician writing the prescription has to be a resident of the state, the number could be assigned at the time the prescription is written. The legislatures could also mandate prescription drug "take back" programs similar to the programs that permit persons to turn in guns. ${ }^{130}$

\section{Doctor Shopping}

The statutes contain no clear definition of "competency"; that determination is made by treating physicians. Thus, opponents of physician-facilitated suicide fear that some patients and their family members may engage in "doctor shopping" so that the patient can be declared competent to request the lethal medication. After a medical professional determines that a patient is incapable of requesting the lethal medication, that should be the end of the story. However, under the current regimes, the patient and the patient's family members can keep having the patient evaluated until a physician concludes that the person is competent. ${ }^{131}$

A prime example of doctor shopping is the situation involving Oregon resident Kate Cheney. ${ }^{132}$ Kate, an eighty-five-year-old woman who lived with her daughter, suffered from terminal stomach cancer. Kate told her daughter, Erika, that she was considering

128 Status of Prescription Drug Monitoring Programs, Alliance OF STATES WITH PRESCRIPTION MONITORING PROGRAMS (Oct. 17, 2012), http://www.pmpalliance.org/pdf /pmp_status_map_2012.pdf; see also Amy L. Caldwell, Comment, In the War on Prescription Drug Abuse, E-Pharmacies Are Making Doctor Shopping Irrelevant, 7 HOUS. J. HEALTH L. \& POL'Y 85, 93-96 (2006) (discussing different types of state PMPs).

129 Oregon Prescription Drug Monitoring Program, OREGON.GOV, http://www.orpdmp .com/ (last visited Oct. 20, 2012).

130 Oregon is attempting to establish such a program. Melanie Leitman, Comment, Water $R_{x}$ : The Problem of Pharmaceuticals in Our Nation's Waters, 29 UCLA J. ENVTL. L. \& POL'Y 395, 423-24 (2011).

131 According to the official Oregon report, six patients choosing assisted suicide in the first year of the law's operations were people who had first been turned down by at least one doctor. OR. HEALTH DiV., OREgON'S DEATH With DigNITY ACT: THE FIRST YEAR'S EXPERIENCE (1998), available at http://public.health.oregon.gov/ProviderPartner Resources/EvaluationResearch/DeathwithDignityAct/Documents/year1.pdf.

132 Herbert Hendin \& Kathleen Foley, Physician-Assisted Suicide in Oregon: A Medical Perspective, 24 Issues L. \& MED. 121, 131-32 (2008). The story about Kate that follows is taken from this source. 
physician-facilitated suicide. Erika accompanied Kate to Kate's treating physician who referred her to a psychiatrist so she could be evaluated. After that examination, the psychiatrist declared Kate ineligible for physician-facilitated suicide because she was cognitively impaired. The psychiatrist was concerned because Kate could not remember recent events and people. He also thought that Kate's family was pressuring her to request the medication.

The psychiatrist's opinion angered Erika, so a representative from Kate's HMO recommended that Kate seek a second opinion from an outside consultant. As a result, Erika took Kate to a psychologist who said that she was competent. The psychologist declared Kate to be capable of requesting the medication even though he noted that Kate was having short-term memory problems and was being pressured by Erika to request the medication. After the opinion by the second psychologist, Kate received the lethal medication.

Erika subsequently sent Kate to live in a nursing home for a week, during which time Kate did not ingest the medication. During her stay at the nursing home, Kate repeatedly begged Erika to let her return home. Finally, Erika relented and took Kate back to her house. It was not until Kate left the nursing home and returned to Erika's house that she took the lethal medication and died. ${ }^{133}$

To resolve issues like the ones raised by Kate's story, the legislature should appoint an independent board to evaluate the competency of a patient requesting the medication when two or more doctors disagree. That board should also be responsible for investigating abuse complaints. To be competent to request the medication, every patient should be required to undergo counseling with an appropriate medical professional. Once the professional declares the person to be capable of requesting the lethal medication, the person would be eligible to get the medication. However, if the professional concludes that the person suffers from clinical depression or another condition that impacts the person's mental capacity, the person would not be approved to receive the medication unless the psychological condition is resolved. 
III

EXPANDING THE AVAILABILITY OF PHYSICIAN-FACILITATED SUICIDE

The current system in place fails to serve the needs of two categories of patients. Some patients, like Mary, who suffer from diseases that destroy the physical body, are not considered terminal because their doctors predict that they will survive longer than six months. In those cases, the doctors use their medical judgments to conclude that the patients will die at some specified time in the future. A patient in that class has a predicted expiration date, but that date is too far in the future for the patient to be labeled as terminal. Another group of patients like Anna suffer from progressive, irreversible brain disorders that gradually destroy their memories and their abilities to learn, reason, and make decisions. Those patients can physically survive their conditions for an indeterminate period of time. Therefore, for purposes of requesting physician-facilitated suicide, those patients are not recognized as being terminal. The law needs to be expanded to serve the needs of patients in both of those groups.

The primary goals cited for legalizing physician-facilitated suicide include the following: permitting terminally ill patients to die before they lose autonomy, easing the pain and suffering of terminally ill patients, and reducing the costs of end-of-life care. Expanding the availability of physician-facilitated suicide is consistent with those objectives.

\section{A. Planning for Terminal}

Under the current statutes, the terminally ill patient must take the lethal medication without assistance. ${ }^{134}$ Once the physician writes the prescription, his or her role in the process ends. To avoid abuse, doctors should not be allowed to help their patients take the lethal medication. Permitting that would be too much like legalizing active euthanasia. ${ }^{135}$ Active euthanasia takes the decision out of the patient's hands and permits the physician to decide when the patient should

134 The statutes provide that nothing in the respective acts authorizes "a physician or any other person to end a patient's life by lethal injection, mercy killing or active euthanasia.” OR. REV. STAT. § 127.880 (2011); WASH. REV. CODE ANN § 70.245.180(1) (West 2011). Hence, physicians may prescribe the medication, but not physically administer it to a patient.

135 Active euthanasia occurs when doctors take some deliberate steps to put their patients to death. Thane Josef Messinger, A Gentle and Easy Death: From Ancient Greece to Beyond Cruzan Toward a Reasoned Legal Response to the Societal Dilemma of Euthanasia, 71 DENV. U. L. REV. 175, 180 (1993). 
die. Such a process would undermine the trust between doctors and patients and the doctor's role as healer. Nonetheless, there should be a procedure which allows the patient to take control of the process by requesting assistance from a friend or family member.

Some patients have progressive diseases that may prevent them from being able to take the medication. For instance, persons with Amyotrophic Lateral Sclerosis (ALS) may only be able to take the medication in the early stages of the disease when they are unlikely to have a "terminal disease" within the meaning of the statutes. Those patients may feel pressure to request and take the lethal medication before they are really ready. They may fear that if they wait too long, they will not be able to take the medication without assistance. ${ }^{136}$ This is a valid concern because the Oregon statute prohibits lethal injection, so people who are unable to swallow may not be able to take the lethal medication. ${ }^{137}$

If the proper safeguards are put in place, those patients should be able to receive physical assistance to take the medication. In some cases, this may entail the medication being administered through a feeding tube. This is consistent with the way that disabled persons have been treated in other areas of the law. For instance, physically incapacitated persons can receive assistance to sign their wills. ${ }^{138}$ One option is for the statutes to be amended to permit the patient to include a clause in the written request form indicating his or her desire to receive assistance when taking the medication. ${ }^{139}$

Under the current versions of the statutes, the person is not permitted to request the lethal medication until he or she has been diagnosed with a terminal disease. ${ }^{140}$ There should be a system in place for a person to request physician-facilitated suicide before he or she becomes terminally ill. For example, a provision for physicianfacilitated suicide could be added to a living will or a health care

136 See Raphael Cohen-Almagor, Euthanasia and Physician-Assisted Suicide in the Democratic World: A Legal Overview, 16 N.Y. INT’L L. REV. 1, 33 (2003), available at Westlaw.

137 David L. Sloss, Note, The Right to Choose How to Die: A Constitutional Analysis of State Laws Prohibiting Physician-Assisted Suicide, 48 STAN. L. REV. 937, 971 (1996).

138 Restatement (ThiRd) OF Prop.: WiLls AND Other Donative Transfers §3.1, cmt. j (1998).

139 See attached sample form.

140 OR. REV. STAT. § 127.805 (2011); WASH. REV. CODE ANN. § 70.245.020 (West 2011). 
directive. ${ }^{141}$ At that time, the person is thinking clearer so the competency issue would be better addressed. Medication and pain may cloud the person's judgment after the doctor starts treating the disease.

Also, the request for the lethal medication will probably be more voluntary prior to the terminal diagnosis. After the person is diagnosed with a terminal disease, he or she may be motivated by fear or guilt to request the medicine. Those emotions may come from not wanting to be a burden on family members. ${ }^{142}$ Even if the person requests the medication in advance, he or she can either rescind the request or simply choose not take the medicine.

\section{B. Getting to Terminal}

My biggest concern is that the opportunity to seek aid in dying is not available to more patients - patients in situations similar to Mary and Anna. The statutes define terminal disease as "an incurable and irreversible disease that has been medically confirmed and will, within reasonable medical judgment, produce death within six months." 143 To extend physician-facilitated suicide in more deserving cases, I recommend removing the durational requirement and broadly interpreting the meaning of terminal.

\section{Physical Conditions}

A person suffering from a disease that cannot be cured or adequately treated and that a doctor reasonably expects to result in death should be considered terminal. If the condition is incurable and irreversible, why should the person have to die within six months? Even some doctors disagree with limiting physician-facilitated suicide to persons who are predicted to die within six months. ${ }^{144}$ The longer

141 There are three main types of advance directives. JESSE DUKEMINIER, ROBERT H. SitKoff \& JAMES Lindgren, WiLls, TRUST, AND ESTATES 457 (8th ed. 2009). In instructional directives like living wills, the person states the level of medical treatment he or she wants to receive in the event he or she becomes incompetent or terminal. Id. In proxy directives like durable health care power of attorneys, the person appoints a third party to make health care decisions in the event the person is not able to do so. Id. In hybrid directives, the person both appoints a third party to make medical decisions and indicates his or her treatment preferences. Id.

142 Kawai, supra note 99, at 797.

143 OR. REv. STAT. § 127.800(12) (2011); WASH. REv. CODE ANN. § 70.245.010(13) (West 2011).

144 See Franklin G. Miller et al., Regulating Physician-Assisted Death, 331 NEW ENG. J. MED. 119 (1994). 
the person is expected to suffer, the more desperately that person needs the option of getting the lethal medicine.

It does not seem fair that Mary, who was predicted to die in eight months, would have to suffer for two months before she was eligible to request the medicine. Once a doctor diagnoses a person with an incurable disease that is expected to result in death, that should be sufficient to trigger the application of the physician-facilitated suicide statute. Otherwise, the patient may take steps to hurry the progression of the disease so that they can get to the six-month mark with the minimum amount of suffering. For example, the person may refuse treatment or not take the prescribed medication.

Mary was forced to suffer because her cancer was not aggressive enough. However, she still had to live with the physical pain caused by the disease and the emotional pain of knowing that her body was being attacked by a disease that would kill her. The legislatures should remove the six-month requirement and give a person who has been diagnosed with an incurable and irreversible disease the opportunity to request the lethal medication.

If the six-month requirement is removed, persons may be worried that patients with chronic illnesses or disabled persons may be considered terminal. Members of the public would probably be uncomfortable with a system that permits those persons to request the lethal medication. But I am not advocating that the legislatures remove the terminal requirement. Thus, the availability of physicianfacilitated suicide would still be limited to persons suffering from medical conditions that doctors reasonably expect to result in death in a certain time period-however, that time period may be shorter or longer than six months.

Another option available to the legislatures is to adopt the definition of terminal illness included in the Uniform Rights of the Terminally Ill Act (URTIA). ${ }^{145}$ Under the terms of that statute, a terminal condition is one that is "incurable and irreversible." "146 The condition must be one that a doctor predicts will "result in death within a relatively short time" unless the patient receives lifesustaining treatment. ${ }^{147}$ The drafters intentionally used the phrase "relatively short time" instead of requiring death to occur within a

145 UNIF. RIGHTS OF THE TERMINALLY ILL ACT (1989).

146 Id. § 1(9).

147 Id.; Marguerite Ann Chapman, The Uniform Rights of the Terminally Ill Act: Too Little, Too Late?, 42 ARK. L. REV. 319, 350 (1989). 
certain time period. By using that broad phrase, the drafters hoped to give physicians the flexibility to evaluate patients on a case-by-case basis. ${ }^{148}$ Several states have adopted versions of the URTIA. ${ }^{149}$

A final possibility is for terminal to be triggered by the stages of the disease. Most diseases have several stages. ${ }^{150}$ Once the patient is in the end stage of the disease, he or she should be classified as terminal. Some conditions like end-stage renal failure are fatal, but doctors cannot predict exactly when the patient will die. Patients with that condition can live and suffer for years.

The focus should be on the progression of the disease and not on the amount of time that the person is predicted to live. For instance, a person diagnosed with stage-two breast cancer may progress to stage four faster than someone diagnosed with stage three. If the person is in the final stage of the disease, the next stage is death. Thus, that person should be considered to be terminal for purposes of requesting the lethal medication.

\section{Brain Disorders}

Presently, in order to be a candidate for physician-facilitated suicide, the person must be diagnosed with a condition that results in physical death. Thus, persons like Anna are not permitted to seek assistance to exit gracefully. To remedy this, the legislature should remove the death requirement from the definition of terminal or redefine death to include non-physical death. The changes would apply to persons suffering from dementia and other progressive, irreversible brain disorders. Dementia is a gradual and progressive loss of memory, thinking, and reasoning skills. ${ }^{151}$ One example of dementia that could be classified as a terminal mental condition is Alzheimer's disease. $^{152}$

148 UNIF. RightS OF THE TERMINALLY ILL ACT § 1 cmt. (1989).

149 E.g., ARK. CODE ANN. §§ 20-17-201 to 20-17-218 (West, Westlaw through 2012 Fiscal Sess.); MONT. CODE ANN. §§ 50-9-101 to 50-9-505 (West, Westlaw through 2011 laws); NEV. REV. StAT. ANN. §§ 449.535 to 449.690 (West, Westlaw through 2011 76th Reg. Sess.).

150 See generally Hunter J. Shkolnik, Overcoming Defenses and Developing Winning Themes in the Failure to Diagnose Case, 2005 ATLA-CLE 487 (describing the stages of cancer), available at Westlaw AAJCLE.

151 James D. Gallagher \& Cara M. Kearney, Note, Representing a Client with Diminished Capacity: Where the Law Stands and Where it Needs to Go, 16 GEO. J. LEGAL ETHICS 597, 597 (2003).

152 See Bruce Jennings, Freedom Fading: On Dementia, Best Interests, and Public Safety, 35 GA. L. REV. 593, 595-96 (2001). 
A person who is suffering from an incurable and irreversible mental disease that significantly impairs his or her quality of life should be considered to be suffering from a terminal condition. Thus, the person should be given the option of selecting physicianfacilitated suicide. The person can achieve that goal by making physician-facilitated suicide a part of planning for incapacity. To that end, the person should be able to include his or her preferences in a living will or another type of advance directive. The person should also be able to choose physician-facilitated suicide in the earlier stages of his or her disorder.

In the alternative, the courts and legislature should broadly interpret the word "death" to include mental death as well as physical death. The definition of death is still evolving because of advances in medical technology. Thus, the law has recognized different definitions of death. Historically, "death" was defined as the cessation of a person's heart and lung functions; a person was declared dead when the heart stopped beating. ${ }^{153}$

However, medical advances have made it possible for a person to breathe artificially and for the heart to beat indefinitely. This became a problem when the person was an organ donor. ${ }^{154}$ To keep the organs viable, the patient was kept on a ventilator. As a result, the person was breathing and had a heartbeat. Thus, under the legal definition of death, the person was still alive. Doctors were reluctant to harvest organs from a live person. ${ }^{155}$

In response, Dr. Henry Beecher and a group of other physicians formed an ad hoc committee at the Harvard Medical School to consider expanding the definition of death. ${ }^{156}$ The committee issued a

153 R. Alta Charo, Biological Determinism in Legal Decision Making: The Parent Trap, 3 TEX. J. WOMEN \& L. 265, 273 (1994).

154 See Martin S. Pernick, Brain Death in a Cultural Context: The Reconstruction of Death, 1967-1981, in THE DEFINITION OF DEATH: CONTEMPORARY CONTROVERSIES 911 (Stuart J. Youngner et al. eds., 1999) (discussing a 1960s Harvard report recommending redefining death, citing respirators and transplants as reasons).

155 Cf. Kirsten Rabe Smolensky, Defining Life from the Perspective of Death: An Introduction to the Forced Symmetry Approach, 2006 U. CHI. LEGAL F. 41, 45-47 (2006) (discussing the debate in the 1960s and 1970s about the definition of death in light of advances in transplant technology).

156 See Tom Stacy, Death, Privacy, and the Free Exercise of Religion, 77 CORNELL L. REV. 490, 518-19 (1992). 
report advocating for the recognition of whole-brain death. ${ }^{157}$ Kansas became the first state to recognize brain death statutorily. ${ }^{158}$

In 1980, the President's Commission for the Study of Ethical Problems in Medicine proposed a model statute to expand the definition of death. The result of that proposal was the Uniform Determination of Death Act (UDDA). The Act states, "An individual who has sustained either (1) irreversible cessation of circulatory and respiratory functions [heart death] or (2) irreversible cessation of all functions of the entire brain, including the brain stem [whole-brain death], is dead."159 Some persons contend that the law should recognize higher brain death. Persons supporting that theory of death argue that the irreversible loss of higher brain functions, including personality, memory, and consciousness, is technically death. ${ }^{160}$

The brain dies in stages, so the option of terminal mental disorders should not be removed from the table. ${ }^{161}$ But life is not just breathing; it is living. Once a brain disorder causes a person's quality of life to be totally depleted, that person should have the option of being declared mentally terminal. The purpose of the physician-facilitated suicide statute is to permit a person to die with dignity. ${ }^{162}$ Persons suffering from incurable and irreversible brain disorders may experience even more indignities than persons suffering from terminal physical conditions.

If Anna had been given the option in the earlier stage of her disease to select physician-facilitated suicide, she might have requested the lethal medication. To prevent abuse, persons suffering from brain disorders should have to preselect physician-facilitated suicide prior to their diagnosis. Even after the diagnosis, if the doctor indicates that the person is still capable of making an informed decision, he or she should be able to follow the procedure to request the lethal medication.

157 Id.

158 Samantha Weyrauch, Comment, Acceptance of Whole-Brain Death Criteria for Determination of Death: A Comparative Analysis of the United States and Japan, 17 UCLA PAC. BASIN L.J. 91, 102-03 (1999).

159 Unif. DETERMinATION OF DEATH ACT § 1 (1980).

160 See T.A. Tucker Ronzetti, Comment, Constituting Family and Death Through the Struggle with State Power: Cruzan v. Director, Missouri Department of Health, 46 U. MiAMI L. REV. 149, 201 (1991).

161 Kathleen L. Paliokas, Note, Anencephalic Newborns as Organ Donors: An Assessment of "Death" and Legislative Policy, 31 WM. \& MARY L. REV. 197, 202 (1989).

162 See generally About Us, DEATH WITH DIGNITY NAT’L CTR., http://www.deathwith dignity.org/aboutus (last visited Oct. 20, 2012). 


\section{CONCLUSION}

Persons suffering from physical conditions that will lead to death in six months should not be the only persons permitted to exit gracefully. As long as the safeguards in the statutes are followed, there is no good reason to prohibit persons suffering from irreversible and incurable physical diseases that lead to death from being classified as terminal.

In addition, persons diagnosed with irreversible and incurable brain disorders, like severe dementia or Alzheimer's disease should be able to avail themselves of the rights provided by the physician-facilitated suicide statutes. Alzheimer's patients suffer a slow, painful death. They revert to childhood and forget everyone around them. The mental death they suffer is similar to the physical death experienced by terminally physically ill patients. During the early stages of the disease, most persons are still competent enough to request physicianfacilitated suicide. Therefore, the statutes should be amended or interpreted to give them that option. The Oregon and Washington statutes should be amended to give patients like Mary and Anna the chance to exit this life gracefully. 
APPENDIX

REQUEST FOR MEDICATION

TO END MY LIFE IN A HUMANE

AND DIGNIFIED MANNER

I, mind.

I am suffering from , am an adult of sound has determined is a terminal disease and which has been medically confirmed by a consulting physician.

I have been fully informed of my diagnosis, prognosis, the nature of medication to be prescribed and potential associated risks, the expected result, and the feasible alternatives, including comfort care, hospice care, and pain control.

I request that my attending physician prescribe medication that will end my life in a humane and dignified manner.

In the event that I am unable to take the medication without assistance, I appoint as the person I would like to assist me.

INITIAL ONE:

I have informed my family of my decision and taken their opinions into consideration.

I have decided not to inform my family of my decision.

I have no family to inform of my decision.

I understand that I have the right to rescind this request at any time.

I understand the full import of this request and I expect to die when I take the medication to be prescribed. I further understand that although most deaths occur within three hours, my death may take longer and my physician has counseled me about this possibility.

I make this request voluntarily and without reservation, and I accept full moral responsibility for my actions.

Signed:

Dated:

\section{DECLARATION OF WITNESSES}

We declare that the person signing this request:

(a) Is personally known to us or has provided proof of identity; 
(b) Signed this request in our presence;

(c) Appears to be of sound mind and not under duress, fraud, or undue influence;

(d) Is not a patient for whom either of us is attending physician.

Witness1/Date

Witness 2/Date 
